\title{
Comparative statement analysis of span structures with a reinforced concrete and orthotropic plate under the exposure of solar radiation
}

\author{
Sergey Gridnev ${ }^{*}$, Igor Podlesnykh, Aleksandr Rezunov, and Rinat Mukhtarov \\ Voronezh State Technical University, 20 let Oktyabrya st., 84, Voronezh, 394006, Russia
}

\begin{abstract}
Carried out a comparative analysis especially the exposure to solar radiation on the stress-strain state (SSS) of span structures with orthotropic slabs of reinforced concrete. Determine the character limit of the temperature distribution in the elements of the two types of spans according to the results of field measurements. Conducted calculation of Stress-Strain State on specific cases of solar radiation with the use of the developed finite element (FE) models of two types of span structures in the platform LIRA SAPR. The results of SSS features obtained for a steelreinforced concrete superstructure and a metal superstructure with an orthotropic slab are compared. It is shown that the uneven daytime change in the temperature field under the influence of solar radiation has a significantly different nature of effect on the stress-strain state of elements of metal and steel-reinforced concrete span structures.
\end{abstract}

\section{Introduction}

In the practice of bridge construction, various types of road bridges are used. Today, one of the most common are steel-reinforced concrete and metal spans with an orthotropic slab. Such spans, which are internally statically indeterminate many times over, perceive temperature effects in a complex way, especially when their elements are unevenly heated. In this case, the nature of the temperature distribution for each type of superstructure can be very diverse. Therefore, the stress-strain state (SSS) from the effect of solar radiation for each type of superstructure has its own characteristics and depends on many factors (design features, materials used, location, etc.) and their combination.

When analyzing scientific publications on the topic of research, the articles [1-2] devoted to the influence of solar radiation on the work of spans were noted.Foreign experience in the

*Corresponding author: gridnev_s_y@rambler.ru 
field of the influence of solar radiation [3-7] is mainly aimed at studying the strength of structures under the influence of temperature loads.

The authors of the article carried out a number of works devoted to the construction of the technique and, with its help, the study of the temperature effect on spans with reinforced concrete and orthotropic slabs. The article [8] examines the stress-strain state of the steelreinforced concrete span structure together with the clothing of the driving track for the purpose of preservation and durability of the top layer of asphalt concrete. The work [9] is devoted to the analysis of the temperature distribution in the layers of the pavement of the steel-reinforced concrete span structure and its influence on the formation of longitudinal cracks in the asphalt concrete pavement in the area above the main beams. In studies [1012], the nature of the distribution of the temperature field along the height of the crosssection was studied, the influence of solar radiation on the stress-strain state and the safety of the asphalt concrete pavement was noted.The article [13] defines the temperature limits at which there are discrepancies in the results of calculating the SSS based on field measurements of the span under the influence of solar radiation with the results of calculations, in accordance with the recommendations of regulatory documents. In works $[14,15]$, studies were carried out during the cold season and a significant effect of temperature effects on the distribution of stresses in the elements of the bridge structure was noted. Recommendations on the need to verify the results of measurements by a noncontact pyrometer of the span structure elements under the influence of solar radiation according to the readings of a contact thermometer are given in article [16]. Work [17] is devoted to assessing the effect of daily and annual temperature fluctuations on the magnitude of stresses in the elements of the span with an orthotropic slab. The article [18] describes a technique for performing field measurements on a span structure when exposed to solar radiation. Full-scale measurements were carried out at the object of study, which make it possible to determine in detail and comprehensively the nature of the temperature distribution in the elements of a metal span with an orthotropic plate.

To take into account the asphalt concrete pavement in terms of the effect of solar radiation, modern approaches to the design of pavement structures for driving tracks have been studied. Articles [19-21] are devoted to the analysis of the design features of road pavements on spans, the main provisions for the design of pavement structures on orthotropic and reinforced concrete slabs are described.

\section{Objectives of the study}

1. Based on the results of field measurements, determine the nature of the temperature distribution over the thickness of the pavement layers and the height of the cross-section in the steel-reinforced concrete and metal span structures from the effects of solar radiation

2. Reveal the features of the temperature fields of elements of two types of spans in similar cases of exposure to solar radiation

3. To carry out a comparative calculation of the SSS in two typical cases of exposure to solar radiation, using the developed finite element models of span structures

4. Comparison of the SSS results obtained for the steel-reinforced concrete superstructure and the metal superstructure with an orthotropic slab.

\section{Description of research objects}

The object of research is two spans:

1) steel-reinforced concrete superstructure of the road bridge over the Malaya Kozhva River. (Fig. 1, a) [10] 
2) a metal superstructure with an orthotropic slab of the road bridge across the river. A crow near the town of Borisoglebsk in the Voronezh region (Fig. 1, b). [13]

a)

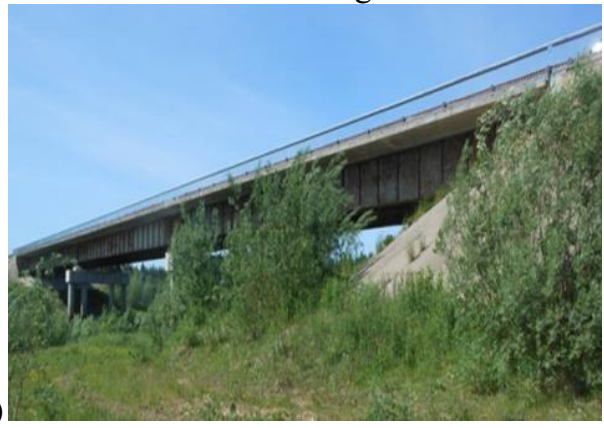

b)

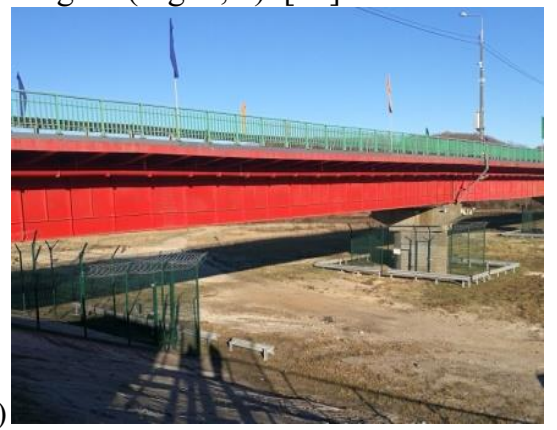

Fig. 1. Object of study:

a) steel-reinforced concrete superstructure; b) metal superstructure

The main characteristics of the span structures are summarized in Table 1.

Table 1. Main characteristics of the Span Structures

\begin{tabular}{|c|c|c|}
\hline Main characteristics & $\begin{array}{c}\text { Reinforced concrete span } \\
\text { structure }\end{array}$ & $\begin{array}{c}\text { Span structure with } \\
\text { orthotropic slab }\end{array}$ \\
\hline Span length & $42.5 \mathrm{~m}$ & $43.1 \mathrm{~m}$ \\
\hline Span width & $13.20 \mathrm{~m}$ & $11.34 \mathrm{~m}$ \\
\hline $\begin{array}{c}\text { The height of } \\
\text { the superstructure }\end{array}$ & $2.52 \mathrm{~m}$ & $2.4 \mathrm{~m}$ \\
\hline Pavement layers & $\begin{array}{c}\text { 1. Waterproofing layer } \\
\text { Crushed stone-mastic asphalt } \\
\text { concrete }\end{array}$ & $\begin{array}{c}\text { 1. Waterproofing layer } \\
\text { 2. Cast asphalt concrete } \\
\text { 3. Dense asphalt concrete }\end{array}$ \\
\hline
\end{tabular}

\section{Approaches to accounting for exposure to solar radiation}

Comparison of the nature of the effect of solar radiation in the summer season on two types of superstructures is carried out.

Under the conditions of exposure to solar radiation, a series of field measurements of the fields of daily temperature fluctuations of the span were performed using two types of instruments to verify the results obtained. The temperature was measured at several points of the span structure elements. On the day of the field measurements, a reading of $35^{\circ} \mathrm{C}$ of the maximum air temperature was recorded.

The air temperature for the steel-reinforced concrete superstructure is assumed to be $36^{\circ} \mathrm{C}$, which corresponds to the peak reading in July in Voronezh 2017.

For two types of spans, 2 similar cases of the effect of solar radiation on the spans were considered:

1. Heating is observed mainly in the main beam, due to the low position of the sun above the horizon (Fig. 2);

2. Heating is observed predominantly of the upper layer of the pavement, due to the high position of the sun above the horizon (Fig. 3). 
a)

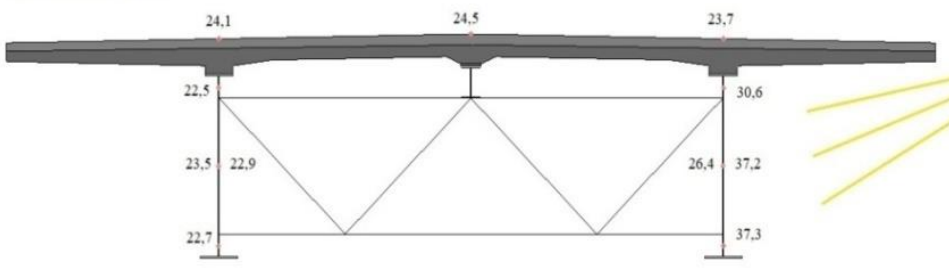

b)

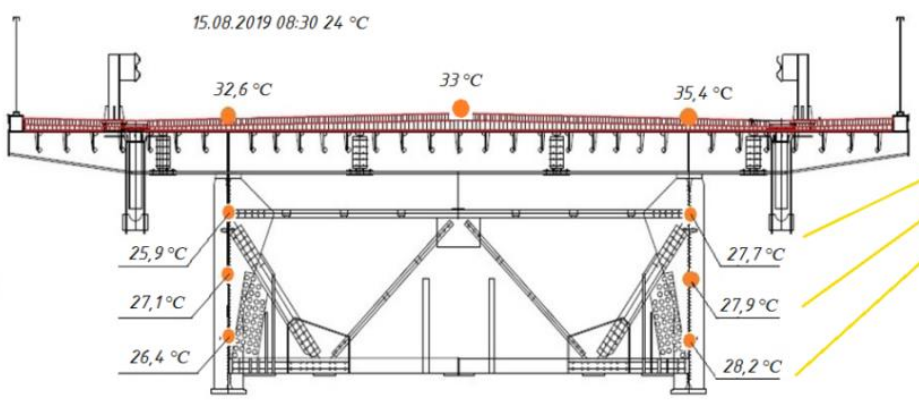

Fig. 2. The first case of exposure to solar radiation (heating of the main beam): a) steel-reinforced concrete superstructure; b) superstructure with orthotropic slab

$\begin{array}{llll}28.07 .2017 \quad 14-00 \quad 36^{\circ} & 0\end{array}$

a)
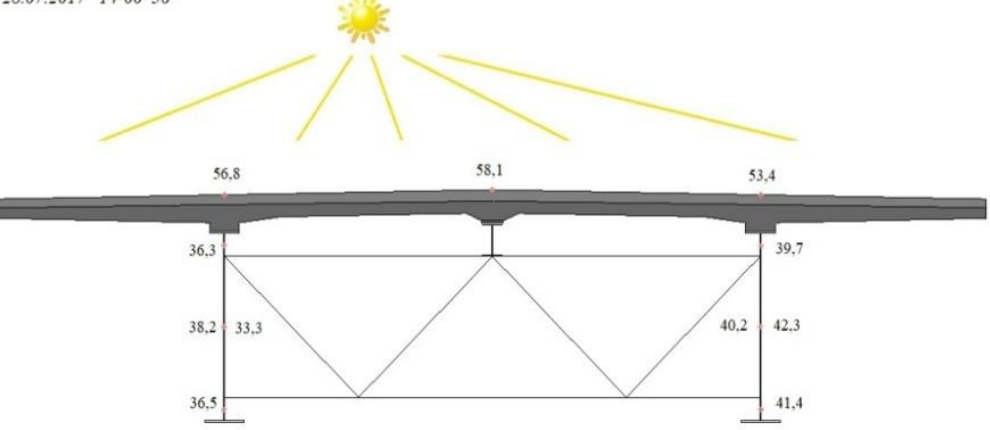

15.08.2019 $14: 3035^{\circ} \mathrm{C}$

b)

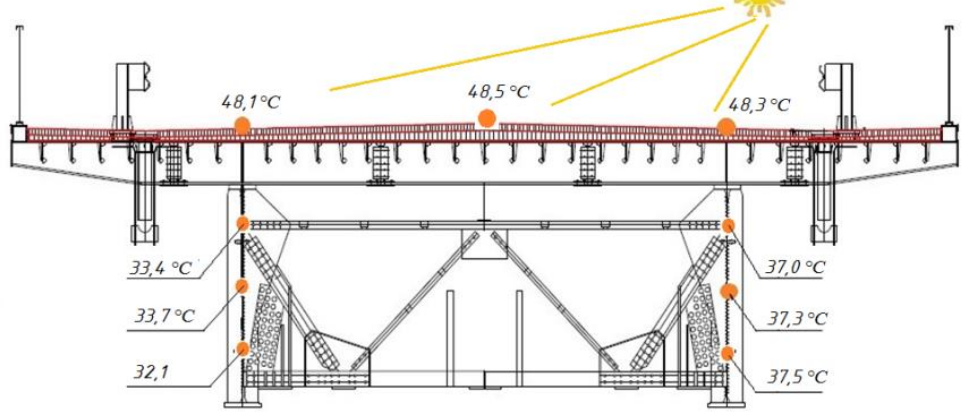

Fig. 3.The second case of exposure to solar radiation (heating of the upper layer of the pavement): a) steel-reinforced concrete span structure; b) span structure with orthotropic slab 
At a similar air temperature at the same time, the main beam in the steel-reinforced concrete spam structure heats up more than the main beam in the metal spam structure by $4.8^{\circ} \mathrm{C}$.

When exposed to direct sunlight on the top layer of the pavement, the surface temperature of the cast asphalt concrete (in the steel-reinforced concrete spam structure) was $9.6^{\circ} \mathrm{C}$ higher than the surface of the dense asphalt concrete (in the metal spam structure). The main results are summarized in Table 2.

Table 2. Temperature of span structure elements

\begin{tabular}{|c|c|c|}
\hline $\begin{array}{c}\text { Temperature of span } \\
\text { structure elements }\end{array}$ & $\begin{array}{c}\text { In a span structure with a } \\
\text { reinforced concrete slab }\end{array}$ & $\begin{array}{c}\text { In a span structure with an } \\
\text { orthotropic slab }\end{array}$ \\
\hline Maximum air temperature & $36^{\circ} \mathrm{C}$ & $35^{\circ} \mathrm{C}$ \\
\hline $\begin{array}{c}\text { Maximum pavement } \\
\text { temperature }\end{array}$ & $58,1^{\circ} \mathrm{C}$ & $48,5^{\circ} \mathrm{C}$ \\
\hline $\begin{array}{c}\text { Maximum temperature of the } \\
\text { main beam }\end{array}$ & $42,3^{\circ} \mathrm{C}$ & $37,5^{\circ} \mathrm{C}$ \\
\hline
\end{tabular}

\section{Description of the FE model used}

Models of two types of superstructures were developed in a specialized modern FE complex (Fig. 4), including layers of pavement and allowing the calculation of temperature loads.

a)

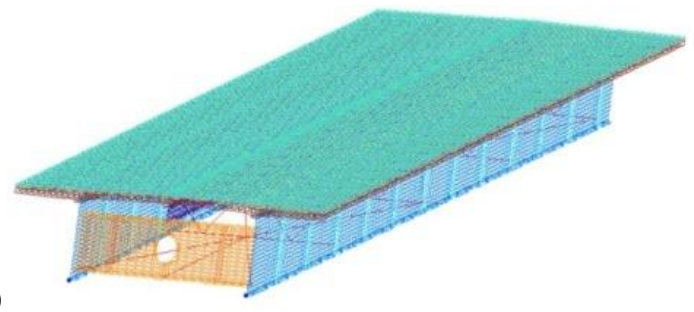

b)

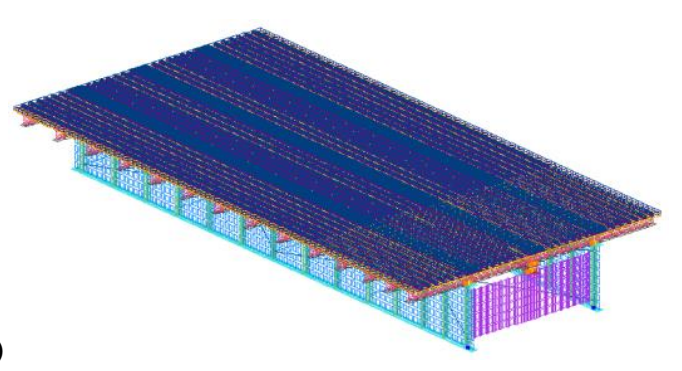

Fig. 4. FE model of span structure:

a) steel-reinforced concrete span structure; b) span structure with orthotropic slab

The main parameters of the elements of spans [19-21] used in the design models are given in table. 3 . 
Table 3. Parameters of superstructure elements

\begin{tabular}{|c|c|c|c|}
\hline Construction type & $\begin{array}{c}\text { Elastic modulus, } \\
\mathrm{MPa}\end{array}$ & $\begin{array}{c}\text { Poisson's } \\
\text { ratio }\end{array}$ & $\begin{array}{c}\text { Volumetric weight, kN / } \\
\mathrm{m} 3\end{array}$ \\
\hline Metal Constructions & 206000 & 0.3 & 77.0 \\
\hline $\begin{array}{c}\text { Reinforced concrete slab (class } \\
\text { B30) }\end{array}$ & 32500 & 0.2 & 24.5 \\
\hline $\begin{array}{c}\text { Waterproofing layer } \\
\text { Crushed stone-mastic asphalt } \\
\text { concrete }\end{array}$ & 687 & 0,3 & 17.66 \\
\hline Cast asphalt concrete & 8503 & 0,22 & 22.56 \\
\hline Dense asphalt concrete & 4501 & 0,22 & 22.56 \\
\hline
\end{tabular}

Using a software package for modeling thermal fields, the nature of the temperature distribution over the thickness of the pavement layers and the height of the cross-section of the span structure was determined, taking into account the difference in material properties (Fig. 5).

a)

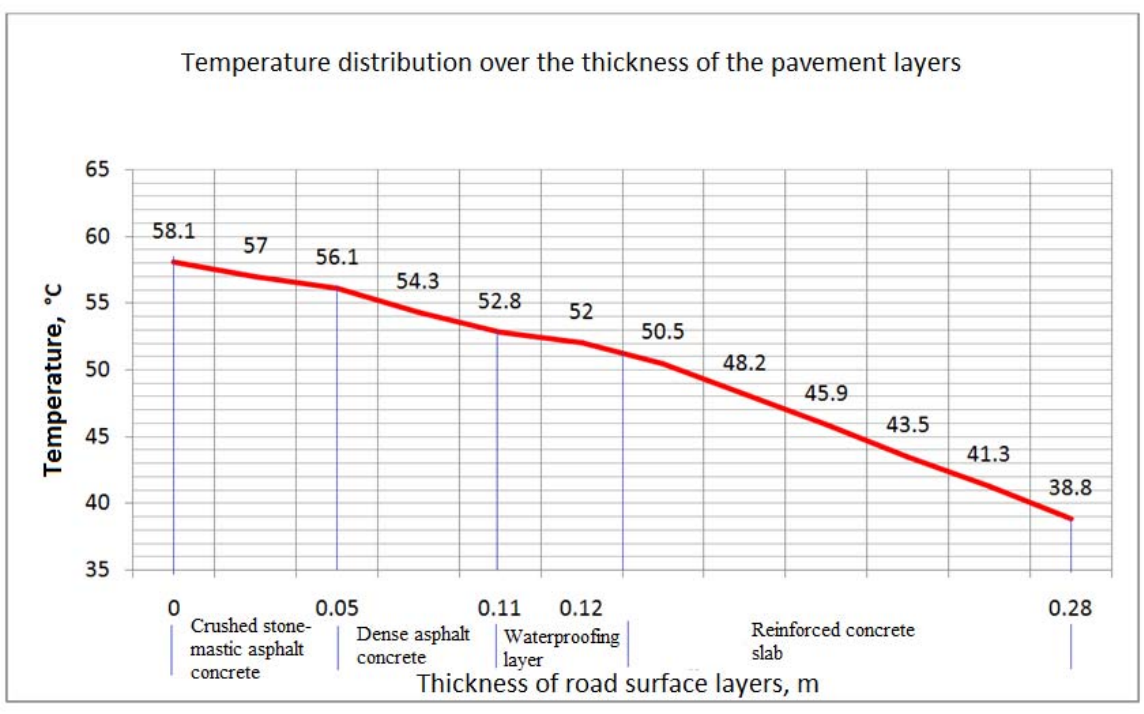


b)

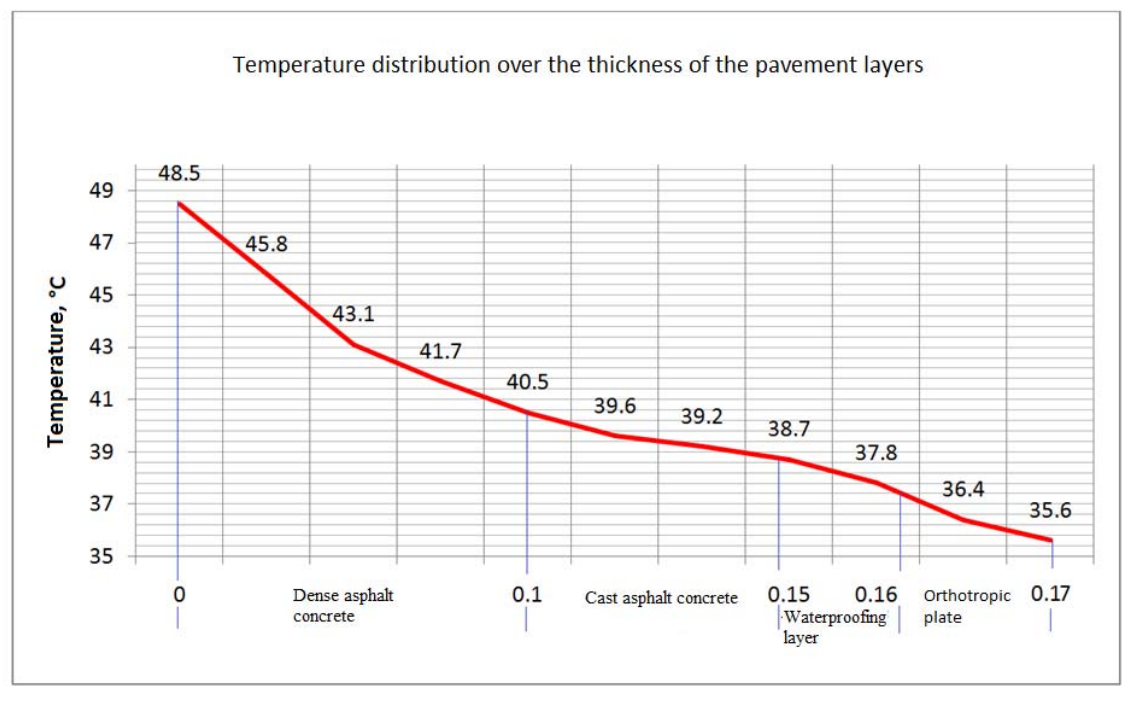

Fig. 5. Temperature distribution over the height of the cross-section:

a) in a steel-reinforced concrete span structure, b) in a span structure with an orthotropic slab

\section{Analysis of the results of numerical studies}

The features of the change in the stress-strain state of the span structure during the day in the summer season at high temperatures are revealed on the basis of the analysis of the results of field measurements. A comparative analysis of the calculation results for two types of spans is made.

Comparison of stresses in the main beams is shown in Figure 6.

a)
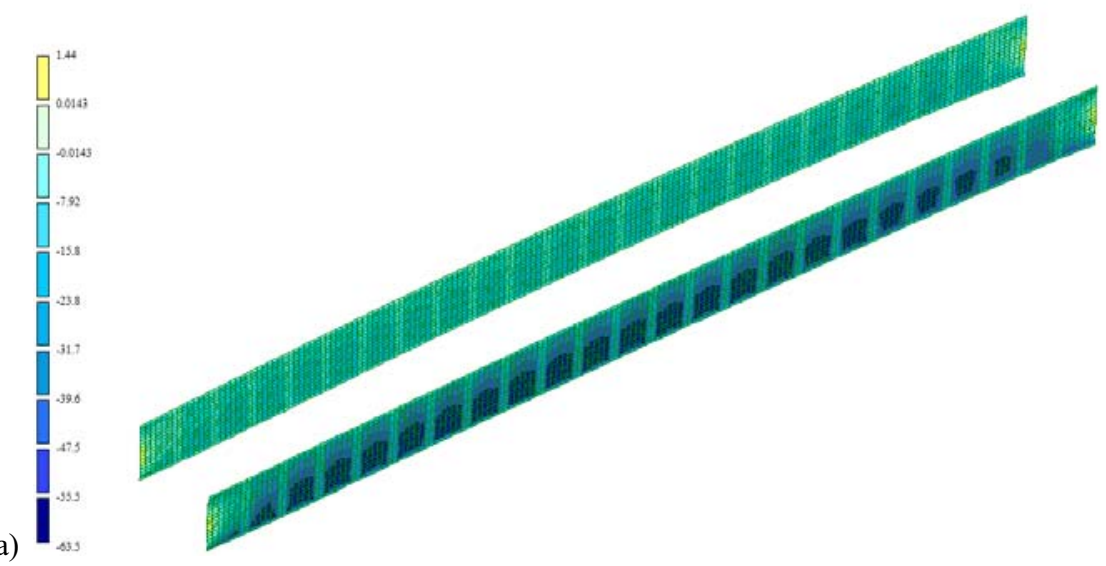


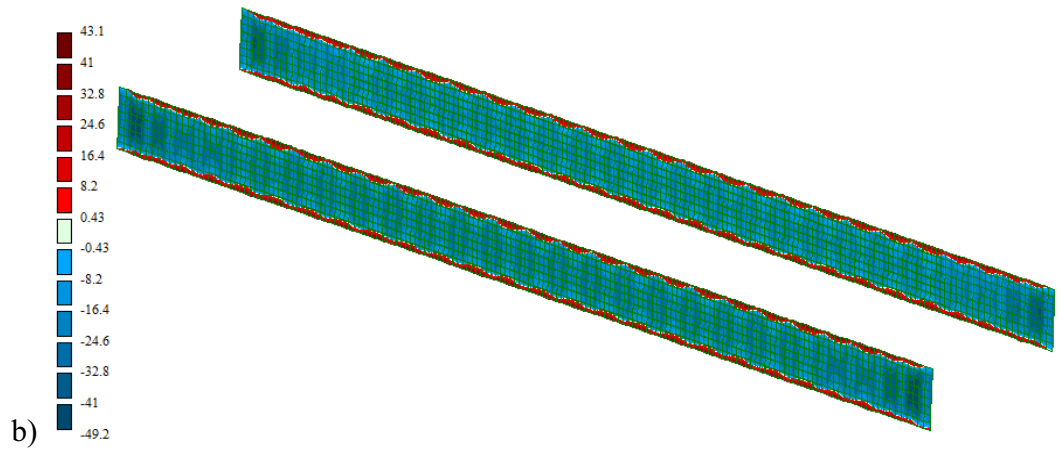

Fig. 6. Stresses in the main beams:

a) in a steel-reinforced concrete span structure, b) in a span structure with an orthotropic slab

The maximum stress in the main beam in the steel-reinforced concrete span structure is 14.3 MPa higher than the stress in the main beam in the metal span structure. Comparison of stresses in the upper pavement layer of two spans is carried out in a similar way. Despite the lower temperature of the top layer of the pavement in the metal superstructure, the stress of dense asphalt concrete is $21.5 \%$ higher than the stress of poured asphalt concrete (in the steel-reinforced concrete superstructure).The maximum stresses in the orthotropic slab exceeded the stresses in the reinforced concrete slab by $20.9 \mathrm{MPa}$. The maximum voltages from exposure to solar radiation in two types of spans, for ease of comparison, are given in Table 4.

Table 4. Comparison of stresses in two types of span comparisons

\begin{tabular}{|c|c|c|c|c|}
\hline \multirow{2}{*}{ Span structure element } & \multicolumn{2}{|c|}{$\begin{array}{c}\text { Reinforced concrete } \\
\text { span structure }\end{array}$} & \multicolumn{2}{c|}{$\begin{array}{c}\text { Metal span structure with } \\
\text { orthotropic slab }\end{array}$} \\
\cline { 2 - 5 } & 1 case & 2 case & 1 case & 2 case \\
\hline Top layer of pavement & 0,78 & 1,07 & 0,9 & 1,3 \\
\hline Main beams & $-63,5$ & $-68,5$ & $-35,7$ & $-49,2$ \\
\hline $\begin{array}{c}\text { Reinforced concrete and } \\
\text { orthotropic slab }\end{array}$ & 10,9 & 21,6 & 33,6 & 42,5 \\
\hline
\end{tabular}

\section{Conclusions}

1. Analysis of the results of field measurements showed that when exposed to solar radiation, the surfaces of the elements in the steel-reinforced concrete span structure heated up more than in the metal span structure with an orthotropic slab.

2. It was found that the stresses in the main beam in the steel-reinforced concrete span structure exceed the stresses in the main beam in the metal span structure.

3. The results of numerical studies showed that the maximum stresses in the orthotropic slab exceeded the stresses in the reinforced concrete slab. In this case, the stress of dense asphalt concrete exceeds the stress of poured asphalt concrete.

4. It is shown that the uneven daytime change in the temperature field under the influence of solar radiation has a significantly different nature of the effect on the SSS of elements of metal and steel-reinforced concrete spans. Therefore, at the design stage, it is important to 
take into account not only the temperature and climatic conditions, the features of the effect of solar radiation, but also the design features of the bearing systems of the transport structure.

The methodology for calculating the stress-strain state of two main types of load-bearing systems of transport structures on the effect of solar radiation has been developed and tested. The nature of the temperature distribution in the steel-reinforced concrete and metal spans from the effects of solar radiation has been determined based on the results of comprehensive field measurements. A comparative analysis of the temperature fields of elements of two types of spans in similar cases of exposure to solar radiation has been carried out. Comparison of the results of stress-strain state of the bearing systems of a steelreinforced concrete span structure and a metal span structure with an orthotropic slab is carried out.

\section{References}

1. V.O. Mishutin. The need to take into account temperature strains at projection and construction of bridge structures. The modern technologies. System analysis. Model operation, № 3 (43): p.203-208 (2014). (in Russian).

2. O.I. Bezbabicheva, A.V. Bilchenko, A.G. Kislov. Prediction of temperature stresses in front beams of bridge structures. Science and progress of transport. Messenger of Dnepropetrovsk National University of Railway Transport, №33: p.28-31 (2010) (in Russian).

3. Cun Ren Jiang, Jian Min Ren, Zhuo Ling Wang. Research of Temperature Field of Long Span Concrete Box Girder Bridge Caused by Solar Radiation. Applied Mechanics and Materials, Vols. 256-259: P.1635-1639. (2013)

4. Linren Zhou, Yong Xia, James M. W. Brownjohn, Ki Young Koo. Temperature Analysis of a Long-Span Suspension Bridge Based on Field Monitoring and Numerical Simulation. Journal of Bridge Engineering, Vol. 21, Issue 1. (2016)

5. XuMing Song, Hani Melhem, Jun Li, QingYuan Xu, LiJun Cheng. Effects of Solar Temperature Gradient on Long-Span Concrete Box Girder during Cantilever Construction. Journal of Bridge Engineering, Vol. 21, Issue 3. (2016)

6. Bo Chen, Yu-zhou Sun, Gan-jun Wang, Ling-yan Duan, “Assessment on Time-Varying Thermal Loading of Engineering Structures Based on a New Solar Radiation Model", Hindawi Publishing Corporation, Mathematical Problems in Engineering, vol. 2014, Article ID 639867, 15 pages. (2014).

7. G. D. Zhou and T. H. Yi, "Thermal load in large-scale bridges: a state-of-the-art review," International Journal of Distributed Sensor Networks, vol. 2013, Article ID 217983, 17 pages. (2013).

8. I.S. Podlesnykh, S.Yu. Gridnev. Calculation of steel reinforced concrete spans with account of the road base. The experience of the past - look to the future: 7 International Scientific and Practical Conference of Young Scientists and Students: conference proceedings, P.193-198. (2017). (in Russian).

9. S.Yu. Gridnev, I.S. Podlesnykh. Calculation of deflected mode of steel reinforced concrete spans with account of temperature effect in the road base layers. Structural Mechanics and structures, №2(15) - P.75-84. (2017). (in Russian).

10. I.S. Podlesnykh, S.Yu. Gridnev, N.A. Barchenkova. Analysis of influence of solar radiation on the deflected mode of steel-reinforced concrete span. Russian journal of 
transport engineering, [online], 2(5). Available at: https://t-s.today/PDF/12SATS218.pdf (in Russian). DOI: 10.15862/12SATS218 (2018).

11. S. Yu Gridnev, I. S. Podlesnykh. Influence of solar radiation on the safety of the top layer of the pavement of an iron-concrete span structure, Collected materials of the XIX International Scientific and Technical Conference "Actual problems of the construction, construction industry and industry". p. 34-36. (2018). (in Russian).

12. S. Yu Gridnev, I. S. Podlesnykh. Temperature distribution along the height of the cross section of the steel concrete bridge span of a highway bridge, Collected materials of the XIX International Scientific and Technical Conference "Actual problems of construction, construction industry and industry". p. 36-36. (2018). (in Russian).

13. I.S. Podlesnykh, S.Yu. Gridnev, N.A. Barchenkova. Verifying Regulatory Documents for Solar Radiation Level Control When Estimating Stress-Strain State of the Spans Based on the Ortho-tropic Slab. The 24th International Scientific Conference MECHANIKA-2019, p.116-122. (2019).

14. S. Yu. Gridnev, I. S. Podlesnykh. The influence of uneven heating on the stress distribution in the elements of the superstructure with orthotropic slab. Collected materials of the XX International Scientific and Technical Conference "Actual problems of the construction, construction industry and industry". p. 108-110. (2019). (in Russian).

15. S. Yu. Gridnev, I. S. Podlesnykh. Features of the temperature field in the elements of the superstructure of the road bridge at close to zero negative temperatures. Collected materials of the XX International Scientific and Technical Conference "Actual problems of the construction, construction industry and industry". p. 110-112. (2019). (in Russian).

16. I.S. Podlesnykh, S.Yu. Gridnev, Yu.I. Skalko. Clarification of the stress-strain state of the superstructure with orthotropic slab taking into account solar radiation. Russian journal of transport engineering, [online] 4(6). Available at: https://ts.today/PDF/15SATS419.pdf (in Russian). DOI: 10.15862/15SATS419 (2019).

17. S. Yu. Gridnev, I. S. Podlesnykh, Yu.I. Skalko, A.V. Rezunov. Estimating the influence of solar radiation at different seasons on the mode of deformation of a span structure with an ortrotropic plate. Archives for Technical Sciences No 23,p.59-66. (2020)

18. S. Yu. Gridnev, I. S. Podlesnykh. Technique for measuring the temperature field of a span with an orthotropic slab under the influence of solar radiation / Collection of materials of the XXI International Scientific and Technical Conference "Actual problems of construction and construction industry", p.62-68. (2020). (in Russian).

19. M.A. Telegin. Simulation of the work of the road surface on the steel orthotropic plate of the bridge. Vestnik SibADI, № 3 (25), p.63. (2012). (in Russian).

20. M.A. Telegin. Road clothing on orthotropic bridge slabs. Road power, № 35, p. 34-39. (2011). (in Russian).

21. I.G. Ovchinnikov, E.V. Zinchenko, V.N. Kuzhel. Analysis of road pavement structures used in bridge construction. Roads. Innovations in road construction, №52, p. 52-55. (2011). (in Russian). 